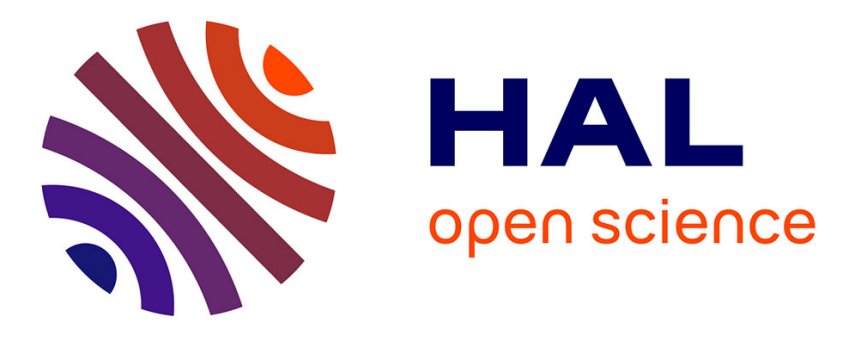

\title{
Local stress-induced effects on AlGaAs/AlOx oxidation front shape
}

Fares Chouchane, Guilhem Almuneau, Nikolay Cherkashin, Alexandre Arnoult, Guy Lacoste, Chantal Fontaine

\section{- To cite this version:}

Fares Chouchane, Guilhem Almuneau, Nikolay Cherkashin, Alexandre Arnoult, Guy Lacoste, et al.. Local stress-induced effects on AlGaAs/AlOx oxidation front shape. Applied Physics Letters, 2014, 105 (4), pp.41909 - 41909. 10.1063/1.4892094 . hal-01721161

\section{HAL Id: hal-01721161 \\ https://hal.science/hal-01721161}

Submitted on 2 Mar 2018

HAL is a multi-disciplinary open access archive for the deposit and dissemination of scientific research documents, whether they are published or not. The documents may come from teaching and research institutions in France or abroad, or from public or private research centers.
L'archive ouverte pluridisciplinaire HAL, est destinée au dépôt et à la diffusion de documents scientifiques de niveau recherche, publiés ou non, émanant des établissements d'enseignement et de recherche français ou étrangers, des laboratoires publics ou privés. 


\section{Local stress-induced effects on AIGaAs/AIOx oxidation front shape}

F. Chouchane, G. Almuneau, N. Cherkashin, A. Arnoult, G. Lacoste, and C. Fontaine

Citation: Appl. Phys. Lett. 105, 041909 (2014); doi: 10.1063/1.4892094

View online: https://doi.org/10.1063/1.4892094

View Table of Contents: http://aip.scitation.org/toc/apl/105/4

Published by the American Institute of Physics

\section{Articles you may be interested in}

Observation of overstrain in the coalescence zone of AIAs/AIOx oxidation fronts

Applied Physics Letters 98, 261921 (2011); 10.1063/1.3606385

\section{Scilight}

Sharp, quick summaries illuminating the latest physics research 


\title{
Local stress-induced effects on AIGaAs/AIOx oxidation front shape
}

\author{
F. Chouchane, ${ }^{1,2}$ G. Almuneau, ${ }^{1,2, a)}$ N. Cherkashin, ${ }^{2,3}$ A. Arnoult, ${ }^{1,2}$ G. Lacoste, ${ }^{1,2}$ \\ and C. Fontaine ${ }^{1,2}$ \\ ${ }^{1}$ CNRS, LAAS, 7 avenue du colonel Roche, F-31400 Toulouse, France \\ ${ }^{2}$ Univ de Toulouse, UPS, LAAS, F-31400 Toulouse, France \\ ${ }^{3}$ CNRS, CEMES, 29 Rue Jeanne Marvig, 31055 Toulouse Cedex 4, France
}

(Received 17 June 2014; accepted 23 July 2014; published online 31 July 2014)

\begin{abstract}
The lateral oxidation of thick AlGaAs layers $(>500 \mathrm{~nm})$ is studied. An uncommon shape of the oxide tip is evidenced and attributed to the embedded stress distribution, inherent to the oxidation reaction. Experimental and numerical studies of the internal strain in oxidized $\mathrm{Al}_{\mathrm{x}} \mathrm{Ga}_{1-\mathrm{x}} \mathrm{As} / \mathrm{GaAs}$ structures were carried out by dark-field electron holography and finite element methods. A mapping of the strain distribution around the AlGaAs/oxide interface demonstrates the main role of internal stress on the shaping of the oxide front. These results demonstrate the high relevance of strain in oxide-confined III-V devices, in particular, with over-500-nm thick AlOx confinement layers. (C) 2014 AIP Publishing LLC. [http://dx.doi.org/10.1063/1.4892094]
\end{abstract}

Thanks to its electrical insulating properties and low refractive index, aluminum oxide ( $\mathrm{AlOx}$ ) obtained from the wet oxidation of $\mathrm{Al}_{\mathrm{x}} \mathrm{Ga}_{1-\mathrm{x}} \mathrm{As}(0.9 \leq \mathrm{x} \leq 1)$ is used to improve electrical and optical confinements in several III-V devices such as Vertical Cavity Surface Emitting Lasers (VCSELs), ${ }^{1}$ Metal Semiconductor Field Effect Transistors (MESFETs), ${ }^{2}$ large bandwidth Bragg mirrors, ${ }^{3}$ integrated micro-lenses, ${ }^{4}$ and non-linear optical devices. ${ }^{5}$ One important issue of this technology is the excess of stress, induced by the oxidation reaction, which affects the mechanical stability and the reliability of the devices. Indeed, the conversion from $\mathrm{Al}_{\mathrm{x}} \mathrm{Ga}_{1-\mathrm{x}} \mathrm{As}$ to aluminum oxide (AlOx) generates a volume contraction of $6 \%-20 \%$ depending on the aluminum content in $\mathrm{Al}_{\mathrm{x}} \mathrm{Ga}_{1-\mathrm{x}} \mathrm{As}$, the layer thickness, and the oxidation process conditions. ${ }^{6}$ Although this phenomenon has been investigated using various physicochemical techniques $^{7-10}$ or/and numerical modeling, ${ }^{10,11}$ all the previous studies have focused on the lateral oxidation of thin $\mathrm{Al}_{\mathrm{x}} \mathrm{Ga}_{1-\mathrm{x}} \mathrm{As}$ films $(<100 \mathrm{~nm})$, while the problem of an internal stress in the case of thick $\mathrm{Al}_{\mathrm{x}} \mathrm{Ga}_{1-\mathrm{x}} \mathrm{As}$ layers $(\sim 1 \mu \mathrm{m})$ has never been analyzed, despite a growing interest due to their involvement in emerging photonic devices. ${ }^{12,13}$ In particular, GaAs-based structures composed of a membrane upon an oxide would be an attractive solution to enable both strong vertical confinement and electrical injection in photonic crystal (PC) laser structures. Furthermore, the use of a thick AlOx low index layer would improve thermal and mechanical properties due to the higher monolithic nature compared to the commonly used air-bridge PC slab structure. ${ }^{14,15}$ In this work, we have combined dark-field electron holography, scanning electron microscopy (SEM), and numerical simulations to get an insight into the strain spatial distribution in partially oxidized GaAs/AlGaAs structures in which the oxidized layer thickness exceeds $500 \mathrm{~nm}$. In the present work, we present a 2D mapping of the strain distribution around the oxide/semiconductor interfaces from which we have identified a link between the effect of the

\footnotetext{
a)E-mail: almuneau@laas.fr
}

internal stress and the oxide front shape, and hence its effect on the oxidation kinetics within such thick layers.

Two GaAs/AlGaAs epitaxial structures (A and B) were grown using solid source molecular beam epitaxy on a GaAs (100) substrate. The vertical structures of samples A and B are composed, from the substrate to the surface, as follows: $\operatorname{GaAs}(500 \mathrm{~nm}) / \mathrm{Al}_{0.98} \mathrm{Ga}_{0.02} \mathrm{As}(1500 \mathrm{~nm}) / \mathrm{GaAs}(1000 \mathrm{~nm})$ and $\operatorname{GaAs}(500 \mathrm{~nm}) / \mathrm{Al}_{0.98} \mathrm{Ga}_{0.02} \mathrm{As}(400 \mathrm{~nm}) / \mathrm{GaAs}(1000 \mathrm{~nm})$, respectively. Stripes with three different widths $(100,200$, and $300 \mu \mathrm{m}$ ) were defined in both epitaxial structures using photolithography and inductively coupled plasma reactive ion etching (ICP-RIE) to allow in the subsequent step the lateral oxidation of the buried $\mathrm{Al}_{0.98} \mathrm{Ga}_{0.02} \mathrm{As}$ from its etched sidewall. Sample A was divided into three pieces that were oxidized at $420^{\circ} \mathrm{C}$ and 500 mbars under saturated $\mathrm{N}_{2} \mathrm{H}_{2} / \mathrm{H}_{2} \mathrm{O}$ mixtures produced at $95^{\circ} \mathrm{C}$, during 5,10 , and $30 \mathrm{~min}$, respectively. Then, the three oxidized pieces were cleaved perpendicular to the stripes, along the oxide propagation direction, and observed by SEM (Hitachi FEG S4800). Sample B was oxidized under the same experimental conditions during 10 min.

As for the oxidation kinetics of thin AlAs layers $(<100 \mathrm{~nm})$, the lateral growth of the AlOx on thick AlGaAs layer $(1.5 \mu \mathrm{m})$ versus time can be described by the DealGrove model ${ }^{16}$ (combination of linear and parabolic kinetics). However, the SEM images of the oxide front (see Fig. 1) show a tilted semiconductor/oxide front for all the oxidized samples forming an angle $\alpha$ relative to the vertical

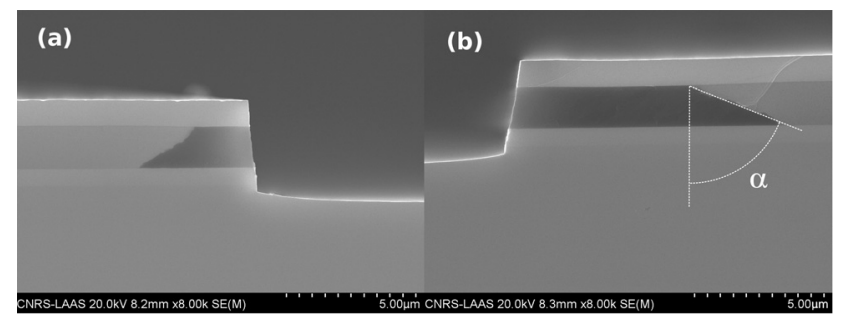

FIG. 1. SEM images of 2 samples, respectively, oxidized during $5 \mathrm{~min}$ (a) and $30 \mathrm{~min}$ (b). The images show an oblique oxide front forming an angle $\alpha$ varying across the oxidation time. 
direction, which is similar for both $\mathrm{AlGaAs}$ thicknesses, but depends on the oxidation duration. Such a slanted interface front shape has never been reported previously. We notice that this angle is mainly formed in the first $10 \mathrm{~min}$ of the oxidation and then increases slightly for longer oxidation time (see Fig. 2). While thin AlAs oxides present a curved front that was associated to an Gibbs-Thomson interface effect, ${ }^{17}$ the oblique shape of the oxide front in the case of the thick layers oxidation could be a consequence of the stress arising from the oxide layer in the initial step of the oxidation process. Tapered oxide shapes of thin oxide layers as widely exploited in VCSELs, results from the vertical oxidation of the AlGaAs surrounding layers whose lower $\mathrm{Al}$ content is specifically chosen. ${ }^{17}$ In the case of the thick oxidized layers, the cap GaAs layer is thinner than the substrate, and therefore the induced stress is preferentially partially elastically relieved from the top side of the AlOx layer. In contrast, at the bottom side of the AlOx layer, the tensile stress is higher. This stress asymmetry is then expected to affect significantly the oxidation kinetics by enhancing the reactive species diffusion as described by Barvosa-Carter et al. ${ }^{18}$ The diffusion coefficient in such stress embedding systems can be expressed as ${ }^{19,20}$

$$
D=D_{0} \exp \left(\frac{a \Omega \sigma_{o x}}{R T}\right)
$$

where $D_{0}$ is the diffusion coefficient independent on stress, $\Omega$ is the molar volume of the diffusion material, $\sigma_{o x}$ is the biaxial stress in the oxide, $R$ is the gas constant, $T$ is the absolute temperature, and $a$ is a positive non-dimensional coefficient.

In Fig. 3, we have fitted the experimental oxidation depths corresponding to the upper and lower bound of the oxidation front, using the Deal-Grove model. Based on a set of parameters determined in a previous work, ${ }^{21}$ we have adjusted the diffusion coefficient $D$ to achieve the best fit between the model and the experimental data. In this way, we have access to the diffusion coefficient. It is found to be 1.58 times higher for the bottom interface than for the upper one. Due to the lack of knowledge of the parameters in the exponential term of Eq. (1), we can only deduce a corresponding ratio between the top and the bottom biaxial stress of $\sigma_{\text {ox_up }} / \sigma_{\text {ox_down }}=-2$. This indicates that the stress is opposed on each side of the oxide front.

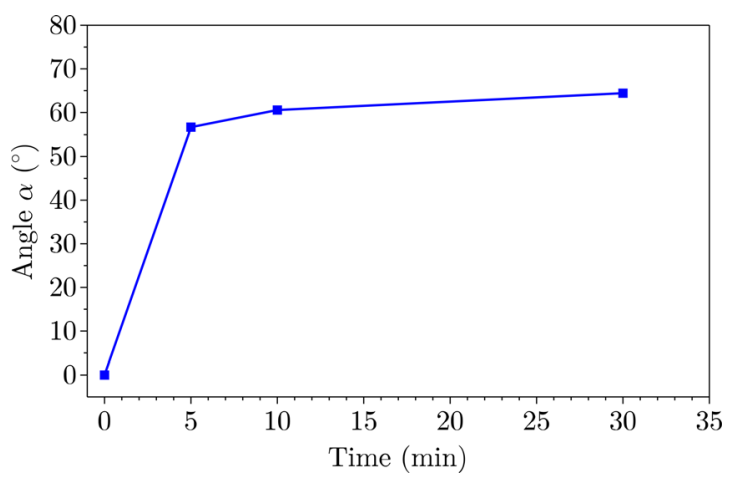

FIG. 2. Evolution of the angle $\alpha$ of the oblique oxide front versus oxidation time.

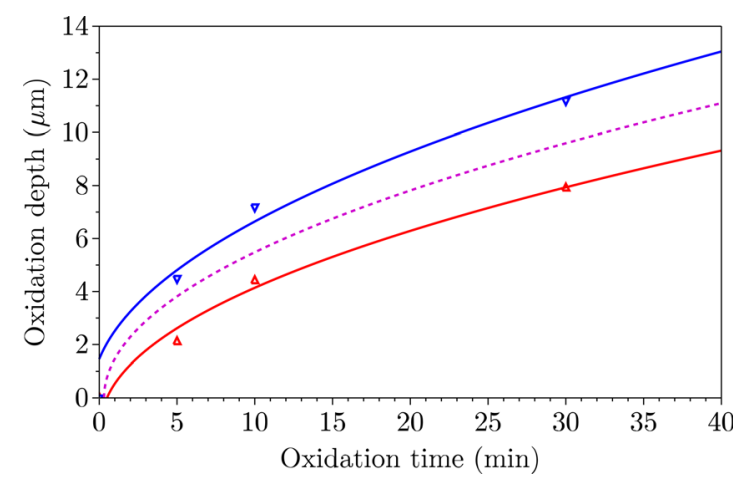

FIG. 3. Measured lateral oxidation depth $v s$ time of the $1.5-\mu \mathrm{m}$ thick $\mathrm{Al}_{0.98} \mathrm{Ga}_{0.02} \mathrm{As}$ for the lower bound (lb) (red downward-pointing triangle) and the upper bound $(u b)$ (blue upward-pointing triangle). The fitted model based on Deal-Grove model and Eq. (1) is given in solid lines for each series of depths (corresponding diffusion coefficients: $D_{l b}=12.6057 \mu \mathrm{m}^{2} / \mathrm{min}$, $\left.D_{u b}=7.9926 \mu \mathrm{m}^{2} / \mathrm{min}\right)$, and the intermediate dotted line corresponds to the Deal-Grove model with a stress-free diffusion coefficient $\left(D_{0}\right.$ $\left.=9.3054 \mu \mathrm{m}^{2} / \mathrm{min}\right)$.

In order to analyze the stress distribution and the resulting strain in the vicinity of the AlOx/AlGaAs interfaces in sample B, a 150-nm-thick cross-sectional lamella were prepared and thinned by means of focused Ga ion beam (FIB) and analyzed by dark-field electron holography using high resolution transmission electron microscopy (HRTEM) (Cs-corrected Tecnai F20). The 2D mapping of the strain field along the $\mathrm{X}$-direction (parallel to the oxide growth direction) and the Y-direction (perpendicular to the oxide growth direction) and the dark-field holograms of the (004) and (220) planes close to the oxidation front are presented in Fig. 4. As the oxide is amorphous, only strain in the semiconductor parts can be observed using this technique. In the $\mathrm{X}$-direction, the results show a tensile strain $\left(\approx 10^{-3}\right)$ in the AlGaAs side of the interface except at the upper corner of the front (green zone) where the strain is found to be compressive $\left(\approx-10^{-3}\right)$. Along the Y-direction, we note a tensile strain in the AlGaAs layer close to the oxide front and the bottom GaAs adjacent zone. The sample can unfortunately not provide any information at the $\mathrm{AlOx} / \mathrm{GaAs}$ upper interface due to the FIB-induced damage. Those results were compared qualitatively with finite element analysis (FEM),

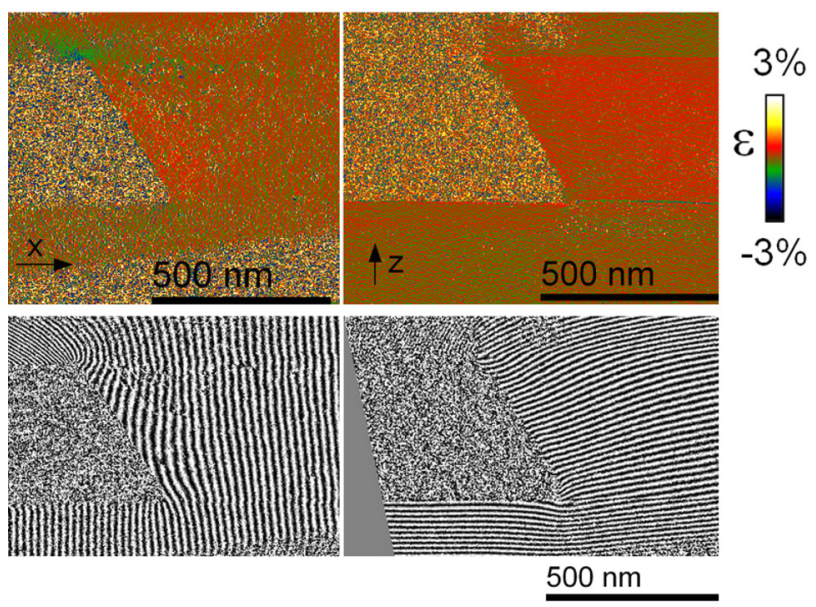

FIG. 4. Measured 2D strain mapping according to the X-and Y-directions (around the oxide front) by HRTEM/dark-field electron holography. 

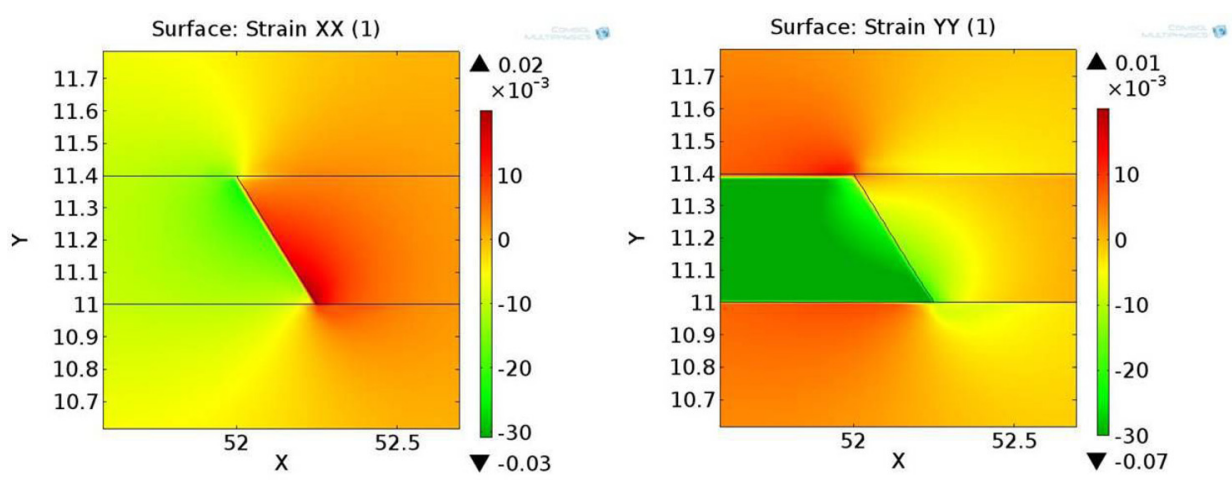

FIG. 5. Calculated 2D strain mapping in the $\mathrm{X}$ - and $\mathrm{Y}$-directions around the oxide front by FEM. since HRTEM measurements are carried out on thin lamella (of about $150 \mathrm{~nm}$ ), whereas FEM simulations are carried out on a $2 \mathrm{D}$ semi-infinite structure. The AlOx volume shrinkage was obtained by attributing a negative dilatation coefficient to the AlOx layer and a zero value to the semiconductor parts. Then, the structure temperature was chosen to induce a contraction of $6.7 \%$, according to our experimental observations. The GaAs and AlGaAs mechanical parameters are well known, contrary to the oxide (AlOx) for which we used $\gamma-\mathrm{Al}_{2} \mathrm{O}_{3}$ parameters $(\mathrm{E}=350 \mathrm{GPa}, \nu=0.21)$. The stress was considered isotropic for both materials. Note that using the Von Mises criterion, we verified that for low oxidation depths the Von Mises stress does not exceed the GaAs yield stress $(2.54 \mathrm{GPa})$ which means that the structures are still elastically strained. The simulation results are represented in Fig. 5. The strain fields in the $\mathrm{X}$ - and Y-directions are in qualitative agreement with the experimental measurements using the dark-field electron holography. The very slight difference between the experimental and the simulation results could be explained on one hand, by the considered approximations since the materials are not perfectly isotropic and the amorphous $\mathrm{AlOx}$ properties are slightly different from those of the crystalline $\gamma-\mathrm{Al}_{2} \mathrm{O}_{3}$ and, on the other hand, since the thickness of the lamella employed for HRTEM observations might slightly change the stress volume distribution.

The mechanical stress induced by volume shrinkage during the wet oxidation of thick AlGaAs layers has been investigated by dark-field electron holography and FEM numerical simulations. The experimental measurements are consistent with modeling and show a tensile strain of some $10^{-3}$ close to the oxide front. Moreover, we have demonstrated that the internal stress due to oxidation impacts the diffusion of the oxidizing species: the stress variation perpendicular to the oxide growth direction leads to the formation of an oblique oxide front whose angle depends on the stress distribution and the oxidation duration. This work finally demonstrate feasibility of stable wet oxidized thick AlGaAs layers, which is highly attractive for the use in GaAs-based PC lasers. This solution is expected to greatly improve the performance of PC lasers by ensuring increased mechanical stability and better heat transfer to the substrate, and moreover, enabling vertical carrier injection within these laser structures.

This work was partly supported by the French RENATECH and CNRS/CEA METSA networks.

${ }^{1}$ D. L. Huffaker, D. G. Deppe, K. Kumar, and T. J. Rogers, Appl. Phys. Lett. 65, 97 (1994).

${ }^{2}$ E. I. Chen, N. Holonyak, and S. A. Maranowski, Appl. Phys. Lett. 66, 2688 (1995).

${ }^{3}$ M. H. MacDougal, P. D. Dapkus, V. Pudikov, H. Zhao, and G.-M. Yang, IEEE Photonics Technol. Lett. 7, 229 (1995).

${ }^{4}$ O. Blum, K. L. Lear, H. Q. Hou, and M. E. Warren, Electron. Lett. 32, 1406 (1996).

${ }^{5}$ M. Savanier, C. Ozanam, L. Lanco, X. Lafosse, A. Andronico, I. Favero, and G. Leo, Appl. Phys. Lett. 103, 261105 (2013).

${ }^{6}$ K. D. Choquette, K. M. Geib, H. C. Chui, B. E. Hammons, H. Q. Hou, T. J. Drummond, and R. Hull, Appl. Phys. Lett. 69, 1385 (1996).

${ }^{7}$ J. P. Landesman, A. Fiore, J. Nagle, V. Berger, E. Rosencher, and P. Puech, Appl. Phys. Lett. 71, 2520 (1997).

${ }^{8}$ Z. Pan, Y. Zhang, Y. Du, H. X. Han, and R. H. Wu, "Stress measurements in oxidized GaAs-AlAs structures by micro-Raman spectroscopy," in IEEE Lasers and Electro-Optics Society Annual Meeting, LEOS'98 (1998), pp. 242-243.

${ }^{9}$ S. A. Blokhin, A. N. Smirnov, A. V. Sakharov, A. G. Gladyshev, N. V. Kryzhanovskaya, N. A. Maleev, A. E. Zhukov, E. S. Semenova, D. A. Bedarev, E. V. Nikitina, M. M. Kulagina, M. V. Maksimov, N. N. Ledentsov, and V. M. Ustinov, Semiconductors 39, 748 (2005).

${ }^{10}$ F. Chouchane, G. Almuneau, O. Gauthier-Lafaye, A. Monmayrant, A. Arnoult, G. Lacoste, and C. Fontaine, Appl. Phys. Lett. 98, 261921 (2011).

${ }^{11}$ R. R. Keller, A. Roshko, R. H. Geiss, K. A. Bertness, and T. P. Quinn, Microelectron. Eng. 75, 96 (2004).

${ }^{12}$ D. J. Ripin, K.-Y. Lim, G. S. Petrich, P. R. Villeneuve, S. Fan, E. R. Thoen, J. D. Joannopoulos, E. P. Ippen, and L. A. Kolodziejski, J. Lightwave Technol. 17, 2152 (1999).

${ }^{13}$ K. Welna, M. Hugues, C. P. Reardon, L. O'Faolain, M. Hopkinson, and T. F. Krauss, Photonics Nanostruct. Fundam. Appl. 11, 139 (2013).

${ }^{14}$ M. Kondow, T. Kawano, and H. Momose, Jpn. J. Appl. Phys., Part 1 48(5R), 050202 (2009).

${ }^{15}$ T. Okabe, M. Morifuji, and M. Kondow, Jpn. J. Appl. Phys., Part 1 53(2), 022701 (2014).

${ }^{16}$ B. E. Deal and A. S. Grove, J. Appl. Phys. 36, 3770 (1965).

${ }^{17}$ R. L. Naone and L. A. Coldren, J. Appl. Phys. 82, 2277 (1997).

${ }^{18}$ W. Barvosa-Carter, M. Aziz, L. Gray, and T. Kaplan, Phys. Rev. Lett. 81, 1445 (1998).

${ }^{19}$ H. Haftbaradaran, H. Gao, and W. A. Curtin, Appl. Phys. Lett. 96, 091909 (2010).

${ }^{20}$ X. Dong, X. Fang, X. Feng, and K.-C. Hwang, J. Am. Ceram. Soc. 96, 44 (2013).

${ }^{21}$ I. Suárez, G. Almuneau, M. Condé, A. Arnoult, and C. Fontaine, J. Phys. D: Appl. Phys. 42(17), 175105 (2009). 